\title{
ASSISTÊNCIA DE ENFERMAGEM DOMICILIAR À FAMÍLIA E PORTADORES DE TRANSTORNO MENTAL: RELATO DE EXPERIÊNCIA
}

\author{
Bruna da Costa $^{1}$, Laryssa Inoue ${ }^{1}$, Vanessa Yukie Kohiyama², Marcelle Paiano ${ }^{3}$, Maria Angélica Pagliarini Waidman ${ }^{4}$
}

\begin{abstract}
RESUMO: Este estudo tem por objetivo relatar as principais dificuldades de familiares e portadores de transtorno mental identificadas durante a realização de visitas domiciliares. Ele é parte de um Projeto de Extensão que teve início em 2008 e atendeu 11 famílias. Nas visitas, utilizou-se um questionário semiestruturado e a análise dos dados obtidos ocorreu por meio da técnica de análise de conteúdo, onde foram identificadas três categorias: desconhecimento das famílias acerca dos sintomas e tratamento do portador de transtorno mental; dificuldade em conseguir e manter emprego; conflitos de relacionamento, com sobrecarga e falta de apoio da família. Conclui-se, que por meio das visitas domiciliares, foi possível conhecer o contexto em que a família está inserida, reconhecendo as possibilidades e necessidades de cada uma, habilitando seus membros para enfrentamento e adaptação de vida em face do transtorno mental.
\end{abstract}

PALAVRAS-CHAVE: Saúde mental; Cuidados de enfermagem; Visita domiciliar.

\section{NURSING HOME CARE TO FAMILY AND INDIVIDUALS WITH MENTAL DISORDER: REPORT OF EXPERIENCE}

\begin{abstract}
This study aims to report the main difficulties of families and individuals with mental disorders identified during home visits. It's part of an Extension Project that began in 2008 and attended 11 families. During the visits we used a semi structured questionnaire, and the data analysis was conducted by the use of the content analysis technique, in which three categories were identified: families' lack of knowledge about the symptoms and treatment of individuals with mental problems, difficulty in achieving and maintaining employment; conflicts in relationships with overload and lack of family support. It is concluded that through home visits it was possible to know the context in which the family is included, recognizing the possibilities and necessities of each family, enabling its members to confront and to make life adaptations in the face of the mental disorder.
\end{abstract}

KEYWORDS: Mental health; Nursing care; Home visit.

\section{ATENCIÓN DE ENFERMERÍA DOMICILIARIAA LA FAMILIAY PORTADORES DE TRASTORNO MENTAL: RELATO DE EXPERIENCIA}

RESUMEN: Este estudio tiene por objetivo relatar las principales dificultades de familiares y portadores de trastorno mental identificadas durante la realización de visitas domiciliarias. És parte de un proyecto de extensión que tuvo inicio en 2008 y atendió 11 familias. En las visitas se utilizó un cuestionario semiestructurado y el análisis de los datos obtenidos ocurrió por medio de la técnica de análisis de contenido donde fueron identificadas tres categorías: desconocimiento de las familias acerca de los síntomas y tratamiento del portador de trastorno mental; dificultad en conseguir y mantener empleo; conflictos de relacionamiento, con sobrecarga y falta de apoyo de la familia. Conclúyese que por medio de las visitas domiciliarias fue posible conocer el contexto en que la familia está inserida, reconociendo las posibilidades y necesidades de cada una, habilitando sus miembros para enfrentamiento y adaptación de vida en fase del trastorno mental. PALABRAS CLAVE: Salud mental; Cuidados de enfermería; Visita domiciliaria.

\footnotetext{
${ }^{1}$ Acadêmica do Curso de Graduação em Enfermagem da Universidade Estadual de Maringá-UEM. Membro do Núcleo de Estudos, Pesquisa, Assistência e Apoio à Família-NEPAAF.

${ }^{2}$ Enfermeira voluntária da UEM.

${ }^{3}$ Enfermeira. Mestre em Enfermagem. Docente do Departamento de Enfermagem da UEM. Membro do NEPAAF.

${ }^{4}$ Enfermeira. Doutora em Enfermagem. Docente do Departamento da Enfermagem da UEM. Membro do NEPAAF.
}

Autor correspondente:

Maria Angélica Pagliarini Waidman

Universidade Estadual de Maringá

Av. Colombo, 5790 - 87020-900 - Maringá-PR, Brasil

Recebido: 01/10/09

E-mail: angelicawaidman@hotmail.com

Aprovado: 30/03/10

Cogitare Enferm. 2010 Abr/Jun; 15(2):354-8 


\section{INTRODUÇÃO}

Até 1980, a assistência ao portador de transtorno mental ocorria centrada exclusivamente nos hospitais psiquiátricos, locais da prática do saber médico. O modelo de atenção em saúde mental se restringia à internação e medicalização dos sintomas manifestados pelo doente, o qual era excluído dos vínculos, das interações e de tudo o que se configurasse como elemento e produto de seu conhecimento ${ }^{(1)}$.

No modelo tradicional de assistência, pouca ênfase é dada às histórias pessoais, aos contextos vividos e às dificuldades de enfrentamento das pessoas acometidas pelo transtorno mental, o que se traduz em um cuidado fragmentado ${ }^{(2)}$. A assistência prestada baseada no modelo hospitalocêntrico aos portadores demonstra que os familiares que procuram ajuda e suporte dos serviços de saúde mental e de seus profissionais apresentam dificuldades das mais variadas ordens. Entre as dificuldades e insatisfações vivenciadas evidenciam-se aquelas relacionadas com as situações de crise, conflitos familiares emergentes, a culpa, o pessimismo por não conseguir visualizar uma saída para os problemas enfrentados e para o isolamento social a que ficam sujeitos os portadores de transtorno mental - para assinalarmos algumas entre tantas outras insatisfações ${ }^{(1)}$.

O modelo psicossocial propõe que fatores políticos, biopsíquicos e socioculturais sejam tomados como determinantes das doenças. Dessa forma, as terapias sairiam do escopo medicamentoso exclusivo, ou preponderante, e o sujeito ganharia destaque como participante principal no tratamento, sendo a família e, eventualmente, um grupo mais ampliado, também incluídos como agentes fundamentais do cuidado ${ }^{(3)}$.

Sabe-se que a Reforma Psiquiátrica deve buscar a emancipação, não meramente política, mas, antes de tudo, pessoal, social e cultural do doente. São pressupostos da Reforma o não-enclausuramento de tantas formas de existência banidas do convívio social; encampar todas as esferas e espaços sociais; permitir um olhar mais complexo que o generalizante olhar do igualitarismo; e buscar a convivência tolerante com a diferença ${ }^{(4)}$.

Diante do exposto, desenvolve-se um Projeto de Extensão intitulado "Assistência de enfermagem a famílias e portadores de transtornos mentais de um grupo de autoajuda”. Assim, neste artigo temos como objetivo relatar as principais dificuldades de familiares e portadores de transtorno mental (TM), identificadas durante a realização de visitas domiciliares (VD) no âmbito deste projeto.

\section{O CENÁRIO}

No ano de 2000, ante a necessidade da construção de uma rede extra-hospitalar de apoio aos portadores de transtorno mental e à sua família, o Centro Integrado de Saúde Mental-CISAM, do Município de Maringá, Estado do Paraná, teve a iniciativa de criar um grupo de autoajuda formado pelas famílias ali atendidas, no qual pudessem compartilhar suas experiências e conhecimentos sobre saúde mental.

As reuniões do grupo eram realizadas, inicialmente, em um restaurante e dirigidas pelos próprios familiares. Devido ao aumento da demanda, em 2001 as reuniões foram transferidas para um colégio, e o grupo passou a ser denominado Associação Maringaense de Saúde Mental-AMSM. Em 2003, a Associação recebeu o prêmio nacional de inclusão social em defesa dos portadores de TM e, em 2006, as reuniões passaram também a ser realizadas no salão comunitário de uma igreja.

As reuniões duram cerca de duas horas, os participantes se posicionam, preferencialmente, em círculo. No início, o coordenador da Associação, realiza a apresentação de todos os participantes e, em seguida, explica a dinâmica da reunião. Os integrantes pedem a palavra ou são convidados a dar o seu depoimento e podem fazê-lo por um período de até 10 minutos. No depoimento, a pessoa costuma falar sobre os motivos que a levaram ao grupo, sua situação atual ou experiências. Os integrantes, que por intermédio da ajuda recebida no grupo atingiram uma situação pessoal e familiar melhor, relatam suas experiências de forma a demonstrar aos demais a eficácia do grupo, que ainda busca progressos.

\section{O PROJETO}

Através da participação voluntária de docentes e acadêmicos na AMSM, verificou-se a necessidade de desenvolver um Projeto de Extensão vinculado ao Núcleo de Estudos, Pesquisa, Assistência e Apoio à Família (NEPAAF) do Departamento de Enfermagem da Universidade Estadual de Maringá, que atendesse à necessidade dessa população. Para isso, criou-se $o$ projeto intitulado "Assistência de enfermagem a famílias e portadores de transtornos mentais de um 
grupo de autoajuda”, cujo objetivo é prestar assistência de enfermagem aos familiares e portadores de transtorno mental no domicílio das famílias que frequentam a AMSM.

Desde o início do projeto, em 2008, foram assistidas por seus integrantes 11 famílias, das quais os principais transtornos relatados pelos pacientes e familiares foram: transtorno afetivo bipolar (cinco famílias), esquizofrenia (duas famílias), depressão (uma família) e pacientes sem diagnóstico fechado (três famílias). Na visita, utiliza-se um questionário semiestruturado com questões abertas e fechadas abordando: identificação da família, perfil de saúde da família e como a Associação tem influenciado ou influencia a vida da família ou do familiar com TM.

Atualmente, o processo de visitas domiciliares está em andamento em cinco das 11 famílias. Deixase de fazer as visitas a pedido da família ou à medida em que verifica-se melhora do paciente através dos relatórios realizados de seu estado no decorrer das VD.

O projeto foi aprovado pelo Comitê de Ética e Pesquisa da Universidade (processo 689/2008). Para a realização das visitas aos familiares, estes foram solicitados a assinar o Termo de Consentimento Livre e Esclarecido. Para garantir o sigilo e anonimato das informações, os sujeitos citados neste estudo são identificados com os nomes fictícios de Rosa, Violeta, Margarida.

A análise dos dados obtidos nas atividades de assistência domiciliar, mediante a estratégia de VD, ocorreu por meio da técnica de análise de conteúdo, que se constitui no conjunto de instrumentos metodológicos em constante aperfeiçoamento e que se aplica às comunicações. Nessa técnica se trabalha as palavras e suas significações; trata-se de uma busca de outras realidades através da mensagem, usando um mecanismo de dedução com base nos indicadores construídos a partir de uma amostra de mensagens particulares ${ }^{(5)}$.

\section{RESULTADOS E DISCUSSÃO}

Através das VD realizadas aos familiares e portadores de transtorno mental, as principais dificuldades relatadas pelos sujeitos foram agrupadas em três categorias: 1) Desconhecimento das famílias acerca dos sintomas e tratamento do portador de TM; 2) Dificuldade do portador de TM em conseguir e manter emprego; e 3) Conflitos de relacionamento, sobrecarga e falta de apoio da família.

\section{Desconhecimento das famílias acerca dos sintomas e tratamento do portador de transtorno mental}

Percebe-se, pelo estudo, que a maioria das famílias e portadores desconhecia as características dos transtornos e os efeitos colaterais da medicação, como por exemplo mo caso da paciente Rosa, 34 anos, portadora de transtorno bipolar. Nos períodos de depressão, a paciente fazia uso das medicações prescritas pelo psiquiatra, mas nos períodos de euforia, por desconhecer as características do transtorno, ela acreditava não ser necessário utilizar medicamentos. Segundo seu relato, nesses períodos, ela apresentava uma grande disposição para executar as tarefas no trabalho e no lar, diferentemente do período depressivo. Em outros momentos, fazia uso de automedicação, caso julgasse necessário, tomando uma dose maior para potencializar os efeitos da medicação.

As formas de se compreender a doença variam de acordo com os sujeitos pesquisados. Alguns associam este fenômeno a uma doença de ordem biológica, psicológica ou social e outros a veem como “desequilíbrio" ou "grande complicação”(6). Não obstante, independentemente da compreensão do familiar sobre o TM, a equipe do projeto faz orientações e oferece apoio às famílias.

Assim, durante as visitas, as famílias foram orientadas sobre a importância do tratamento medicamentoso, bem como sobre seus efeitos colaterais e o período de adaptação. Também foram esclarecidas as dúvidas e questionamentos acerca da fisiopatologia e sintomas do transtorno.

\section{Dificuldades do portador em transtorno mental em conseguir e manter o emprego}

Entre as várias dificuldades pelas quais passa a família e o portador de TM, a que mais sobressaiu foi a desconfiança na relação familiar e, em segundo lugar, os problemas econômicos. A dificuldade financeira é a principal causa de conflitos familiares, pois o cuidador muitas vezes se vê obrigado a assumir o doente mental sozinho, tanto no tocante ao cuidado como quanto ao custeio da casa e do tratamento ${ }^{(7)}$.

Alguns pacientes apresentaram dificuldade em se inserir no mercado de trabalho por não conseguirem se adaptar ao ambiente, dados os efeitos colaterais do medicamento e a falta de compreensão dos empregadores sobre tais dificuldades. Essa situação pode ser exemplificada pelo caso de Violeta, 36 anos, divorciada, 
mãe de uma adolescente de 17 anos, desempregada, diagnosticada como portadora de transtorno afetivo bipolar há 12 anos. Seus principais sintomas são tristeza, desânimo e mania de perseguição. Violeta relatou que durante os períodos de adaptação à medicação, em que os efeitos colaterais se evidenciam, o rendimento profissional é prejudicado, mas, transcor-

rido este período, seu desempenho retorna ao normal. Não obstante, foram nestas situações que se deram as maiores ocorrências de demissão.

A sonolência, efeito colateral de alguns psicofármacos ou parte da sintomatologia clínica, em conjunto com a alteração do comportamento, compromete a participação do portador de sofrimento mental no mercado de trabalho ${ }^{(8)}$. Nesse sentido, os sujeitos foram orientados a expor tal fato aos seus médicos para contar com a possibilidade de alteração dos horários das medicações, além da procura por ambientes de trabalho menos estressantes.

Em Maringá, é realizado um projeto, paralelo à AMSM, de integração e reinserção social aos portadores e familiares de TM, intitulado Projeto Girassol, cujas reuniões são realizadas na própria sede da Associação. Por meio de oficinas de trabalho, confecção de trabalhos manuais e convivência com outros portadores, os participantes podem promover sua saúde e aliviar o sofrimento psíquico, além de obter renda com a venda dos produtos por eles confeccionados. Apesar dos esforços por parte dos pacientes e da comunidade, os portadores de TM encontram grandes barreiras para a inserção no mercado de trabalho. Em uma sociedade ditada pelo capital e pouco permeável às diferenças que existem entre os seres humanos, transformar as relações que existem entre ela e o portador de transtorno psíquico é um dos grandes desafios a serem enfrentados pela Reforma Psiquiátrica ${ }^{(9)}$.

\section{Conflitos de relacionamento, sobrecarga e falta de apoio da família}

Constata-se que o relacionamento familiar torna-se difícil quando o portador de TM passa a fazer cobranças diversas à família, situação muitas vezes relacionada à confusão mental e que gera gastos excessivos. O evento é mais complicado quando a família não sabe reagir diante de tais situações ${ }^{(10)}$.

Quando os familiares compreendem a terapêutica e consentem em colaborar com ela, estão mais propensos a cuidar do paciente de forma adequada; se, por outro lado, o doente não adere à terapêutica medicamentosa, os parentes mais próximos tendem a ficar sobrecarregados por não terem com quem dividir a responsabilidade ${ }^{(11)}$. Com o doente em casa, muitas vezes, o orçamento não atende às necessidades familiares, e as mudanças exigidas ocasionam uma sobrecarga familiar que engloba o desgaste físico e emocional. Ante à realidade, os serviços de saúde devem propiciar uma assistência integral ao doente e à família ${ }^{(12)}$.

Durante as visitas, os pacientes e familiares tinham a liberdade de expressar seus sentimentos e dificuldades na convivência; com a equipe, buscavamse caminhos e alternativas para o enfrentamento dessas situações, tanto para o familiar quanto para o paciente. Citamos, como exemplo dessa situação, a família de Margarida. Os pais acreditavam que a filha, Margarida, 30 anos, mãe de dois filhos e portadora de depressão há 10 anos, apresentava "falta de vontade" em sair do quadro depressivo. Durante as visitas, os pais afirmaram estar sobrecarregados, pois são eles os encarregados dos cuidados a um dos netos e da filha. Eles se encontravam desmotivados a enfrentar o transtorno pelas inúmeras tentativas e tratamento para que a filha saísse do estado depressivo.

Percebe-se que o sofrimento afeta todo o núcleo familiar, o que denota a necessidade de uma assistência voltada a todos os membros. Diante disso, é desenvolvida a comunicação terapêutica com a família, pois a insistência desta na recuperação da saúde do familiar leva a desgastes e sofrimentos, e que nossa presença, por meio da comunicação terapêutica, contribui para a família enfrentar essa situação.

Portanto, mais do que uma aliada na efetivação do modelo psicossocial emergente, a família deve ser encarada como foco de intervenção, para que seus anseios sejam acolhidos e sua sobrecarga aliviada ${ }^{(8)}$.

\section{CONSIDERAÇÕES FINAIS}

Constatou-se que a assistência ao portador de TM e sua família, por meio de visitas domiciliares, é uma importante estratégia para consolidação da Reforma Psiquiátrica no que diz respeito à desinstitucionalização e a reinserção do portador de TM na família e na sociedade. Conhecer o contexto em que a família está inserida permite desenvolver uma assistência que reconheça as possibilidades e necessidades de cada membro e habilitá-los para o enfrentamento e a adaptação de vida em face do transtorno. 
Como integrantes do Projeto de Extensão percebemos a importância da formação profissional com um olhar diferenciado, isento dos estigmas e preconceitos que permeiam a vivência do portador na família e sociedade.

A consolidação e concretização da Reforma Psiquiátrica e do processo de desinstitucionalização acontecem à medida que uma rede de atenção passa a dar suporte à família e ao portador de TM, provendo assistência integral e digna.

Os grupos de autoajuda e a assistência por meio de VD contribuem para o resgate da dignidade do ser humano e são instrumentos facilitadores no desenvolvimento de estratégias de reabilitação psicossocial.

Espera-se que este relato de experiência sensibilize e divulgue conhecimentos sobre a assistência de enfermagem a partir do reconhecimento das características do portador de TM e de sua família, e contribua para a superação da falta de informações e, principalmente, do estigma de que são vítimas.

\section{REFERÊNCIAS}

1. Waidman MAP, Elsen I. O cuidado interdisciplinar à família do portador de transtorno mental no paradigma da desinstitucionalização. Texto Contexto Enferm. 2005;14(3):341-9.

2. Gentile C, Pereira MAO. A doença mental: visão de pacientes psicóticos. Cogitare Enferm. 2005;10(2):17-23.

3. Alverga AR, Dimenstein M. A reforma psiquiátrica e os desafios na desinstitucionalização da loucura. InterfaceComunic Saúde Educ. 2006;10(20):299-316.

4. Nunes M, Juca VJ, Valentim CPB. Ações de saúde mental no programa saúde da família: confluências e dissonâncias das práticas com os princípios das reformas psiquiátrica e sanitária. Cad Saúde Pública. 2007;23(10):2375-84.

5. Bardin L. Análise de conteúdo. Lisboa: Edições 70; 1977.

6. Barroso AGCA, Abreu LM, Bezerra MAA, Ibiapina SLD, Brito HB. Transtornos mentais: o significado para os familiares. Rev Bras Promoc Saúde. 2004;17(3):99108.

7. Pereira MOA, Pereira J.A. Transtorno mental: dificuldades enfrentadas pela família. Rev Esc Enferm. USP. 2003;37(4):92-100.

8. Borba LO, Schwartz E, Kantorski LP. Sobrecarga da família que convive com a realidade do transtorno mental. Acta Paul Enferm. 2008;21(4):588-94.

9. Vianna PCM, Barros S. O significado do cuidado para a família na reabilitação psicossocial do doente mental: uma revisão teórica. REME Rev Min Enferm. 2004;8(1):223-8.

10. Waidman MAP, Gusmão R. Família e cronicidade da doença mental: dúvidas, curiosidades e relacionamento familiar. Fam Saúde Desenvolv. 2001;3(2):154-62.

11. Jorge MSB, RamirezARA, Lopes CHAF, Queiroz MVO, Bastos VB. Representações sociais das famílias e dos usuários sobre participação no tratamento de pessoas com transtorno mental. Rev Esc Enferm USP. 2008;42(1):135-42.

12. Spadini LS, Souza MCBM. A doença mental sob o olhar de pacientes e familiares. Rev Esc Enferm USP 2006;40(1):123-7.

Cogitare Enferm. 2010 Abr/Jun; 15(2):354-8 